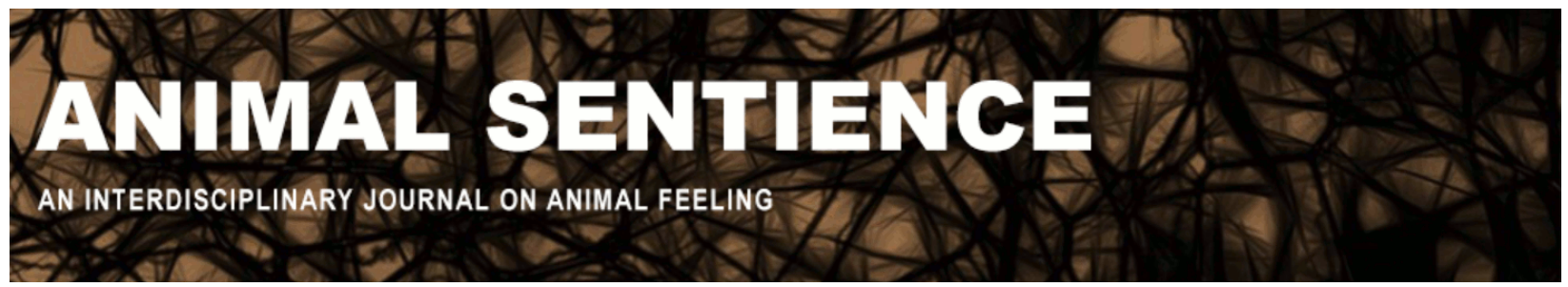

King, Barbara J. (2016) Understanding emotional suffering. Animal Sentience $4(9)$

DOI: $10.51291 / 2377-7478.1036$

Date of submission: 2015-10-05

Date of acceptance: 2015-12-14 (c) (†) 


\title{
Understanding emotional suffering
}

Response to Commentary on King on Animal Grief

\author{
Barbara J. King \\ Department of Anthropology \\ College of William \& Mary
}

\begin{abstract}
In responding to insightful commentaries from 7 scholars, for which I am grateful, I offer new thoughts on whether animals can conceptualize and express signs of grief. I also discuss why I included both weak and strong examples of animal mourning, and how this work may help us think about enhanced welfare for animals, including freedom from emotional suffering.
\end{abstract}

Barbara J. King bjking@wm.edu, Chancellor Professor of Anthropology at the College of William and Mary, writes and speaks about animal thinking, feeling, and welfare. Her article, "When Animals Mourn," in Scientific American was included in the 2014 anthology

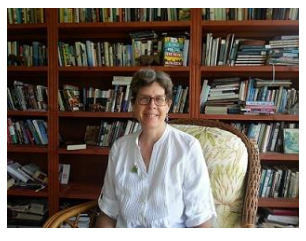
The Best American Science and Nature Writing. King writes weekly for NPR's 13.7 Cosmos and Culture blog. Her next book, Animals We Eat, is forthcoming. http://www.barbarajking.com

Botero. Thanks to Botero for pushing me to think harder about (as she puts it) "the consequences of starting from a perspective that separates an emotion from an expression of an emotion." Is it possible for scientists to distinguish between cases in which animals experience some sort of emotional state but don't express it visibly in signs we recognize, versus those in which animals simply may not be experiencing such a state?

In this regard, I think of the research (as described in How Animals Grieve) by Anne Engh et al. (2006) on wild baboons in Botswana. Engh's team compared the biochemical profiles of female baboons who had witnessed a predator attack and lost a close companion to females who had witnessed an attack but had not lost someone close. Females in the former group had elevated glucocorticoid levels, an indicator of stress and, Engh suggests, of bereavement. In this case, hormone levels indicating stress stand in for felt grief. Can we do better? Within weeks, these females broadened their social networks, for example, of grooming partners. Were they seeking relief from grief? Might some bereaved baboons display no visible changes that would allow us a window into their emotions? The first step is to ask these questions in a wide variety of contexts; perhaps aiming for complementarity between measurement of stress hormones and close observation of survivors' before-andafter behaviors is our best bet moving forward. 
Botero zeroes in on the key factor that I feel underlies the significance of studying animals' expression of grief, and of love: a new avenue for thinking about "the morally right ways" of treating animals. The basic science has value all on its own, yet my central interest is in applying the data to real-world issues. As I noted in the Précis (King), our responsibilities towards animals may be grasped in sharper outline when we understand their emotional as well as their physical suffering.

Gardiner. Yes, animals may interact not only through specific signaling "but also more generally and more continuously by interpreting one another's behaviors," and this is a fundamentally important point. It's one I took up as a central frame when presenting data in a previous book, The Dynamic Dance (2004), on the contingent and unpredictable gestural and postural communication that's ongoing among the African ape individuals, including those I observed and filmed. Updates from Gardiner on modeling efforts regarding mirror neuron systems and demodulation pathways for this sort of communication will be welcome.

Glymour. The duty to try not to like the book is what Glymour takes as his charge! That's an intriguing opening paragraph. I cannot help, in turn, but like his bringing in cattle. (They're in my forthcoming book, Animals We Eat, on animal intelligence and emotion, as are insects, octopuses, fish, goats, and pigs.) I take Glymour's point that I should have done a better job on the matter of whether animals have concepts. It would take pages to review the various ways "concepts" may be understood in ethology, but I do intend something more than grief requiring an object. How might we distinguish between cases in which an animal may grasp that a companion is in some sense permanently gone and those in which the animal understands (and grieves) only the immediate separation from a breathing, moving partner? In How Animals Grieve I recount the story of Bobby, a captive male gorilla who first tries to revive his dead mate and friend Bebe, even to the point of placing celery, Bebe's favorite food, in her hood. When his attempts fail, Bobby begins to wail and bang on the bars of his enclosure. Does that moment mark a change in Bobby's knowledge state, when he grasps the finality of his separation? If so, then this gorilla can be said, in some sense (not necessarily our human sense) to have a concept of death.

Fox Hall. It was exactly my intention to consider alternative hypotheses to grief in explaining an animal survivor's behavior after a companion's death, and I am gratified that Fox Hall found this feature to be a strong one in How Animals Grieve. The scientific study of animal emotion faces something of an uphill battle already (at least among some scientists!), and jumping to too-ready conclusions without careful observations over a period of time, followed by critical thinking about how to interpret what was seen, is a risk. I can think of no way to apply this rigorous principle to a comparative study of anticipatory grief, and while we have no evidence that other animals experience that state, I cannot say for sure that they don't. Might an aspect of an elephant's post-traumatic stress disorder, once she has witnessed the wounding of family members by poachers, be a feeling of anticipatory grief? How would we ever know? Like Fox Hall for me it's impossible to conclude whether our species' knowledge of death's inevitability is a burden or a blessing. On the matter of obituary notices in the newspaper for animals, I say, bring them on: I would be entirely comfortable with my family members' (or my own) obituaries appearing 
on a page graced with others for local, well-loved horses, cats, dogs, rabbits, snakes, fish, and whomever else!

Probyn-Rapsey. How very apt are Probyn-Rapsey's descriptions of our links to and responsibilities for other animals. Yes, we humans do grieve beyond words, very often in ways borrowed from other animals, as the gorilla Bobby's wailing I described in my response to Glymour exemplifies. Yes, agro-business makes meat into an ungrievable commodity. Increasingly, I wish to invite all of us to think about the meaning of animal love and grief as a motivator for no longer denying the reality of other animals' lives.

Proctor. Since the publication of How Animals Grieve, primatologists Bezerra, Philip Keasey, Schiel, and da Silva Souto (2014) have published in the journal Primates an account of a male marmoset monkey (named M1B) in Brazil's Amazonian forest who comforted his dying mate. The female (F1B) had fallen from high in a tree canopy, struck her head on a ceramic object at the tree's base, and lay mortally injured and in evident pain on the forest floor. M1B's "gentle care and attention" to her moved these scientists, who wrote of "compassionate care-taking" by M1B. (M1B also tried to copulate with F1B during this period, a point that demonstrates the complex mix of behaviors that may occur at such a time.)

F1B died within three hours. The researchers didn't take up the question of grief. Certainly M1B's behavior was altered in the immediate moment, but were his normal routines disrupted in subsequent days and weeks at the loss of the female with whom he had been bonded and raised infants for three years? (Marmoset males are very involved fathers.) All we know is that M1B disappeared from the group after three months, and his fate is unknown.

I mention this case because it speaks to Proctor's point that it may be most beneficial to seek evidence of grief among certain monkey species. Marmosets and other pair-bonded species are the ideal candidates for this sort of investigation, precisely because of their tightly knit partnerships and families.


small misunderstanding: it is not the case that when I quote someone in my book, it's meant as a "summary of my beliefs." I do cite Ahere's explanation that she prefers to start with the assumption that animals love others in their own ways. It's a poor scientist, though, who explores a topic like this armed with assumptions, especially regarding a category as broad as "animals," which after all could mean spiders as well as elephants. In fact I indicate this skeptical position in the very next paragraph following the Ahere quote, by noting that if we take up her assumption, "We run the risk of diluting the phenomenon we want to understand." Possibility, not assumption, is where I endeavor to start: the possibility that some animals (that is, a range of vertebrates and invertebrates) demonstrate through their behavior around death that they feel their lives more deeply than many scientists have heretofore suspected. Evidence that supports and does not support that possibility must then be considered. 
How Animals Grieve does include, just as Ristau says, examples based on weak as well as strong evidence for grief. This span, as she notes, is something I take up explicitly in the book's afterword; it's necessary to distinguish dubious cases from strong ones, and the criteria used for doing so, in a field as young as animal thanatology. (I wish Ristau had specified a few of the anecdotes she's dissatisfied with.)

On the topic of equality/superiority, it's nice to see Ristau's acknowledgment that I don't "exactly" suggest that all animals are equal. I am not certain what it would mean to assert that: Equal in their value? To whom? Equal in the profundity of their emotional experiences or their capacities for suffering? Are those metrics the ones of central importance? If so, why? I am not, of course, arguing that "a third-world human" should be subjected to invasive experimentation of some type instead of a monkey or ape, nor that we should cease to create new drugs because those drugs require testing. These issues are important, as are the questions of human social justice with which Ristau ends her commentary: Yet I don't wish to privilege this notion of a competition, an implicit contest to figure out who is "even


National Public Radio, none of us should hesitate to raise our voices for animals and, more importantly, take actions that make lives better for animals. We can do this right alongside raising our voices and taking actions in matters of human social justice.

\section{References}

Bezerra, B. M., Keasey, M. P., Schiel, N., and da Silva Souto, A. 2014. Responses towards a dying group member in a wild New World Monkey. Primates 55(2): 185-188.

Botero, M. 2016. Death in the family. Animal Sentience 2016.040.

Engh, A. L., Beehner, J. C., Bergman, T., J., Whitten, P. L., Hoffmeier, R. R., Seyfarth, R. M., and Cheney, D. L. 2006. Behavioural and hormonal responses to predation in female chacma baboons (Papio hamadryas ursinus). Proceedings of the Royal Society B 273: 707-712.

Fox Hall, T. 2016. Anticipatory grief. Animal Sentience 2016.041.

Gardiner, M. F. 2016. Modulation of behavior in communicating emotion. Animal Sentience 2016.042.

Glymour, C. 2016. The object of grief. Animal Sentience 2016.043.

King, B. J. 2004. The dynamic dance: Nonvocal communication in African great apes. Cambridge: Harvard University Press.

King, B. J. 2013. How animals grieve. University of Chicago Press.

King, B. I. 2016. Animal mourning: Précis of How animals grieve (King 2013). Animal Sentience 2016.004.

Probyn-Rapsey, F. 2016. Love's claim on grief. Animal Sentience 2016.044.

Proctor, H. S. 2016. Monkey say, monkey do, monkey grieve? Animal Sentience 2016.045.

Ristau, C. 2016. Evidence for animal grief? Animal Sentience 2016.046. 